\title{
Vancomycin pharmacokinetics in critically ill neonates receiving extracorporeal membrane oxygenation
}

\author{
Sook Hee An, ${ }^{1}$ Eun Mi Lee, ${ }^{2,3}$ Jae Yeon Kim, ${ }^{3}$ Hye sun Gwak (i) ${ }^{2,4}$
}

${ }^{1}$ College of Pharmacy, Wonkwang University, Iksan, Republic of Korea ${ }^{2}$ Graduate School of Clinical Health Sciences, Ewha Womans University, Seoul, Republic of Korea

${ }^{3}$ Department of Pharmacy, Asan Medical Centre, Seoul, Republic of Korea

${ }^{4}$ College of Pharmacy, Ewha Womans University, Seoul, Republic of Korea

\section{Correspondence to}

Dr Hye sun Gwak, College of Pharmacy \& Division of Life and Pharmaceutical Sciences, Ewha Womans University, Seoul 03760, Republic of Korea; hsgwak@ewha.ac.kr

SHA and EML contributed equally.

Received 10 August 2018 Revised 15 January 2019 Accepted 22 January 2019 Published Online First 20 February 2019

EAHP Statement 6: Education and Research.

\begin{abstract}
Objective This study aimed to characterise vancomycin pharmacokinetics in critically ill neonates undergoing extracorporeal membrane oxygenation.

Methods In a retrospective analysis, the pharmacokinetics of vancomycin were determined in 25 full-term neonates receiving extracorporeal membrane oxygenation and compared with those of matched controls $(n=25)$ not receiving extracorporeal membrane oxygenation.
\end{abstract}

Results The half-life of vancomycin in the neonates undergoing extracorporeal membrane oxygenation was significantly prolonged compared with that in the controls $(17.45 \pm 11.01$ hour vs $5.92 \pm 2.70$ hour $\mathrm{P}<0.001)$. Clearance decreased significantly in the extracorporeal membrane oxygenation group relative to the control group $(0.03 \pm 0.02 \mathrm{~L} / \mathrm{kg} / \mathrm{hr}$ vs $0.08 \pm 0.05 \mathrm{~L} /$ $\mathrm{kg} / \mathrm{hr}, \mathrm{P}<0.001)$. No significant difference was found in the volume of distribution between the two groups $(0.63 \pm 0.30 \mathrm{~L} / \mathrm{kg}$ in the extracorporeal membrane oxygenation group vs $0.57 \pm 0.14 \mathrm{~L} / \mathrm{kg} / \mathrm{hr}$ in control, $\mathrm{P}=0.596)$. Clearance values were significantly correlated with serum creatinine $(r=-0.528, P<0.001)$. In the subgroup analysis using patients with serum creatinine $<0.5 \mathrm{mg} / \mathrm{dL}$, similar results were obtained including significantly prolonged half-life (11.52 \pm 6.31 hour vs $5.44 \pm 2.36$ hour, $P<0.001)$ and decreased clearance $(0.05 \pm 0.02 \mathrm{~L} / \mathrm{kg} / \mathrm{hr}$ vs $0.09 \pm 0.05 \mathrm{~L} / \mathrm{kg} / \mathrm{hr}, \mathrm{P}<0.001)$ in the extracorporeal membrane oxygenation group relative to the control group.

Conclusions Vancomycin clearance decreased significantly in the neonates undergoing extracorporeal membrane oxygenation compared with the controls. Dosing adjustments of vancomycin and close therapeutic drug monitoring are required for the safe and effective management of neonates during extracorporeal membrane oxygenation.

\section{INTRODUCTION}

Extracorporeal membrane oxygenation (ECMO) is a life support system for the management of severe respiratory or cardiorespiratory failure. ${ }^{1}$ Venovenous (VV) ECMO is used for patients with respiratory failure only, while veno-arterial (VA) ECMO support is used in patients with both heart and lung problems. $^{2-4}$ To maintain the ECMO circuit and to treat underlying diseases, patients undergoing ECMO treatment require numerous drugs, such as heparin, analgesics and antibiotics.

In neonates, ECMO is widely used for respiratory failure due to pulmonary hypertension, congenital diaphragmatic hernia or meconium aspiration syndrome, and is used after surgery addressing congenital cardiac defects. ${ }^{5}$ Because ECMO increases the circulating blood volume and transiently alters renal function, the pharmacokinetics of many drugs can be affected. ${ }^{67}$ In addition, the pharmacokinetics of many drugs in neonates are different from those in adults. The volume of distribution $\left(\mathrm{V}_{\mathrm{d}}\right)$ in neonates is usually larger for water-soluble drugs. Neonates also have decreased clearance (CL) of drugs eliminated by glomerular filtration. ${ }^{9}$

Vancomycin is frequently used in neonates with indwelling intravenous catheters to provide coverage for potentially antibiotic-resistant bacterial strains. Because vancomycin is eliminated by glomerular filtration, the CL of vancomycin is related to renal function. ${ }^{10}$ It has been reported that serum creatinine (SCr) has a negative correlation with the CL of vancomycin in neonates. ${ }^{11} 12$ Several studies have been conducted on the effects of ECMO on the pharmacokinetics of vancomycin in neonates and infants. ${ }^{13-15}$ Since poor understanding of vancomycin pharmacokinetics led to an increase in medical costs, ${ }^{16}{ }^{17}$ study of the pharmacokinetic characteristics of vancomycin in patients with ECMO could be of practical importance. However, most studies had small sample sizes and lacked adequate control groups. Moreover, conflicting results have been reported. Therefore, the purpose of this study was to characterise the pharmacokinetics of vancomycin in neonates undergoing ECMO. An additional subgroup analysis was conducted based on SCr levels.

\section{MATERIALS AND METHODS}

\section{Study patients}

This retrospective study was conducted in the Paediatric Intensive Care Unit (PICU) in the Asan Medical Centre from August 2006 to May 2013. This study was approved by the Institutional Review Board of the Asan Medical Centre (IRB \# 2014-0040).

All full-term neonates who received vancomycin during ECMO support were included in the case group (ECMO group). A postconceptional age- and weight-matched control group was randomly selected among patients receiving vancomycin without ECMO support during the same period (non-ECMO group). Patients receiving ECMO for less than 24 hours were excluded. Other exclusion criteria were as follows: vancomycin concentrations sampled at inaccurate times, vancomycin not dosed according to standard regimen and abnormal concentrations (table 1 ).

\section{Administration and monitoring}

Vancomycin was infused over 1 hour at a dose of $10 \mathrm{mg} / \mathrm{kg}$ every 6,8 or 12 hours based on postnatal age and postconceptional age according to standard paediatric dosing recommendations (table 1). ${ }^{18}$ Blood samples were taken after steady state was achieved (ie, after the third dose). The peak blood 


\begin{tabular}{|c|c|c|c|}
\hline PCA (weeks) & PNA (days) & Dosing (mg/kg) & Interval (hr) \\
\hline \multirow[t]{2}{*}{37 to 44} & 0 to 7 & 10 & 12 \\
\hline & $>7$ & 10 & 8 \\
\hline$\geq 45$ & ALL & 10 & 6 \\
\hline
\end{tabular}

PCA, postconceptional age; PNA, postnatal age.

level was measured using samples collected 1 hour after the end of the infusion, and the trough level was obtained $30 \mathrm{~min}$ before the dose. To achieve target trough therapeutic range, routine vancomycin therapeutic drug monitoring was conducted by a pharmacist in cases of initiating or dosing adjustment. Blood samples were analysed using the TDx immunoenzymatic assay (Abbott Laboratories, Abbott Park, IL). The detection limit of the assay was $0.3 \mathrm{mg} / \mathrm{L}$, and the coefficient of variation was $<5 \%$.

\section{Data collection}

The following patient characteristics were recorded: sex, weight, gestational age, postnatal age, postconceptional age, underlying disease diagnosis, paediatric risk of mortality (PRISM) III score, length of PICU stay, mortality, start and end dates of ECMO, ECMO type and SCr. Vancomycin dosage, administration and sampling time, and values for the peak and trough concentrations were also recorded.

\section{Pharmacokinetic analysis}

Pharmacokinetic analysis was performed using the software program CAPCIL (Simkin, Gainesville, FL). Because serum concentrations were collected in the post-distribution phase, a one-compartment model and a first-order kinetic model were used. Patient-specific pharmacokinetic parameters of vancomycin, including half-life $\left(\mathrm{t}_{1 / 2}\right), \mathrm{V}_{\mathrm{d}}$, elimination rate constant $(\mathrm{k})$, and CL, were calculated using the multiple-point linear method. The percentage of cases within the target range for vancomycin trough concentrations $(10-20 \mathrm{mg} / \mathrm{L})$ was analysed.

\section{Statistical analyses}

Continuous variables were compared using the Student's $t$-test: when there were more than two comparison groups, a one-way ANOVA was used. If the variables were not normally distributed, as determined by the one-sample Kolmogorov-Smirnov and Levene tests, additional Mann-Whitney $U$ and KruskalWallis tests were used. The Chi-square test was used to compare categorical variables. Correlation analysis between pharmacokinetic parameters and patient characteristics such as SCr was performed using Pearson's correlation coefficient. Multivariate analysis was performed using variables with a P-value less than 0.05 from univariate analysis. Also an additional subpopulation analysis was performed based on SCr concentrations. P-values $<0.05$ were considered statistically significant. SPSS Version 17.0 for Windows (IBM Corporation, Armonk, NY) was used for all statistical analyses.

\section{RESULTS}

Twenty-five full term neonates (75 peak and trough pairs) who received vancomycin with ECMO support between August 2006 and May 2013 were enrolled in the ECMO group. Nine preterm neonates, one neonate with abnormal drug concentration and one neonate with vancomycin not dosed according to the standard regimen were excluded. The postconceptional age- and bodyweight-matched control group who received vancomycin without ECMO consisted of 25 patients (69 peak and trough pairs). The demographic and clinical characteristics of patients in both the ECMO and non-ECMO groups are shown in table 2. There were no significant differences in baseline characteristics except for PICU survival, underlying diseases, SCr levels and renal replacement therapy. The survival rate was significantly higher in the non-ECMO group than in the ECMO group. SCr levels were significantly higher in the ECMO group than in the non-ECMO group. The mean duration of ECMO was $11.92 \pm 8.13$ days, and the numbers of VV ECMO and VA ECMO cases were eight and 17, respectively. Underlying diseases included congenital heart disease (52\%) and lung disorders (48\%) in the ECMO group, whereas most neonates in the non-ECMO group had congenital heart disease $(88 \%)$. The peak and trough concentrations were measured $2.8 \pm 2.0$ times per patient. The mean number of doses of vancomycin received by each patient was $40.5 \pm 25.0$.

The pharmacokinetic parameters of vancomycin are shown in table 3. In the ECMO group, the $t_{1 / 2}$ was significantly prolonged compared with the values measured in the nonECMO group $(\mathrm{P}<0.001)$. The values for $\mathrm{k}$ and $\mathrm{CL}$ were significantly decreased in the ECMO group compared with those in the non-ECMO group $(\mathrm{P}<0.001)$. No significant difference was found in the $\mathrm{V}_{\mathrm{d}}$ between the two groups. The mean peak and trough levels of vancomycin in the ECMO group were $31.51 \pm 12.82$ and $17.86 \pm 10.04 \mathrm{mg} / \mathrm{L}$, respectively, whereas those in the non-ECMO group were $23.43 \pm 9.65$ and $10.94 \pm 6.93 \mathrm{mg} / \mathrm{L}$, respectively. Thus, peak and trough levels were significantly higher in the ECMO group than in the nonECMO group $(\mathrm{P}<0.001)$. The percentage of neonates with a trough vancomycin concentration of $>20 \mathrm{mg} / \mathrm{L}$ was significantly higher in the ECMO group than in the non-ECMO group (36.0 vs $7.2 \%, \mathrm{P}<0.001)$.

Because vancomycin CL showed a negative correlation with $\mathrm{SCr}(\mathrm{r}=-0.528, \mathrm{P}<0.001)$, pharmacokinetic parameters in the ECMO group were evaluated based on SCr levels. As shown in table 4, as SCr increased, CL values decreased: the mean value in neonates with $\mathrm{SCr}$ of $>1.5 \mathrm{mg} / \mathrm{dL}$ was 5 -fold lower than the mean value in neonates with $\mathrm{SCr}<0.5 \mathrm{mg} / \mathrm{dL}$.

An additional analysis was conducted in patients with $\mathrm{SCr}$ $<0.5 \mathrm{mg} / \mathrm{dL}$ (table 5). Seventeen cases in the ECMO group and 56 cases in the non-ECMO group were included in this analysis. The values of $\mathrm{t}_{1 / 2}$ in the ECMO group were significantly prolonged compared with those in the non-ECMO group $(11.52 \pm 6.31$ hour vs $5.44 \pm 2.36$ hour, $\mathrm{P}<0.001)$. CL decreased significantly in the ECMO group relative to that in the non-ECMO group $(0.05 \pm 0.02 \mathrm{~L} / \mathrm{kg} / \mathrm{hr}$ vs $0.09 \pm 0.05 \mathrm{~L} / \mathrm{kg} / \mathrm{hr}, \mathrm{P}<0.001)$. No significant difference was found in the $\mathrm{V}_{\mathrm{d}}$ between the two groups $(0.75 \pm 0.41 \mathrm{~L} / \mathrm{kg}$ in the ECMO group vs $0.59 \pm 0.14 \mathrm{~L} / \mathrm{kg}$ in control, $\mathrm{P}=0.069$ ). Similar to the results from patients with $\mathrm{SCr}$ $<0.5 \mathrm{mg} / \mathrm{dL}$, in the case of patients having SCr between 0.5 and $1.0 \mathrm{mg} / \mathrm{dL}, \mathrm{t}_{1 / 2}$ in the ECMO group was significantly prolonged compared with that in the non-ECMO group $(12.31 \pm 4.88$ hour vs $7.99 \pm 3.14$ hour, $\mathrm{P}=0.005$ ).

Since patients with ECMO had high levels of SCr, it was difficult to match baseline renal function with the control group. To adjust confounding variables such as renal function and physiologic maturation, multiple linear regression analysis was carried out, including variables with $\mathrm{P}<0.05$ from univariate analysis. ECMO was significantly associated with vancomycin clearance after adjusting potential confounding factors (adjusted $\left.\mathrm{r}^{2}=0.289, \mathrm{P}<0.001\right)$. 
Table 2 Demographic and clinical characteristics of patients

\begin{tabular}{|c|c|c|c|}
\hline & ECMO & Non-ECMO & P-values \\
\hline Patients & 25 & 25 & \\
\hline Pairs of drug concentrations (peak and trough) & 75 & 69 & \\
\hline Gestational age, weeks & $39.01 \pm 1.11$ & $38.80 \pm 1.14$ & 0.511 \\
\hline Postnatal age, days & $8.00 \pm 7.94$ & $10.72 \pm 8.07$ & 0.235 \\
\hline Postconceptional age, weeks & $40.15 \pm 1.40$ & $40.33 \pm 1.47$ & 0.664 \\
\hline Males, n (\%) & $14 / 25(56)$ & $18 / 25(72)$ & 0.239 \\
\hline Bodyweight, $\mathrm{kg}$ & $3.06 \pm 0.36$ & $3.04 \pm 0.36$ & 0.721 \\
\hline PRISM III score at 24 hours (range) & $13.92 \pm 4.80(3-23)$ & $11.04 \pm 5.40(4-27)$ & 0.052 \\
\hline Length of PICU stay, days (range) & $17.44 \pm 10.66(5-45)$ & $17.56 \pm 11.24(4-54)$ & 0.965 \\
\hline PICU survival, $\mathrm{n}(\%)$ & $5(20)$ & $21(84)$ & $<0.001$ \\
\hline Underlying disease & & & 0.004 \\
\hline Congenital heart disease & 13 & 22 & \\
\hline Lung disorder & 12 & 0 & \\
\hline Endocrine disorder & 0 & 1 & \\
\hline Haematologic disorder & 0 & 1 & \\
\hline Achondroplasia & 0 & 1 & \\
\hline Duration of vancomycin therapy, days (range) & $18.96 \pm 9.17(4-38)$ & $20.17 \pm 9.12(3-36)$ & 0.428 \\
\hline Serum creatinine, mg/dL (range) & $1.03 \pm 0.70$ & $0.34 \pm 0.14$ & $<0.001$ \\
\hline Median (IQR) & $0.70(0.50-1.40)$ & $0.32(0.24-0.43)$ & \\
\hline Renal replacement & & & 0.001 \\
\hline Without dialysis, n (\%) & 39 & 64 & \\
\hline CRRT, n (\%) & 16 & 0 & \\
\hline Haemofiltration, $\mathrm{n}(\%)$ & 15 & 0 & \\
\hline $\mathrm{PD}, \mathrm{n}(\%)$ & 1 & 5 & \\
\hline
\end{tabular}

Data are presented as the mean $\pm \mathrm{SD}$ (range) or $\mathrm{n}(\%)$.

CRRT, continuous replacement therapy; ECMO, extracorporeal membrane oxygenation; IQR, interquartile range; PD, peritoneal dialysis; PRISM, paediatric risk of mortality; PICU, paediatric intensive care unit.

\section{DISCUSSION}

The main findings of this study are that there was no significant difference in $\mathrm{V}_{\mathrm{d}}$, but a longer $\mathrm{t}_{1 / 2}$ and a lower CL were observed in ECMO patients compared with non-ECMO patients. Similar results were obtained after controlling for SCr: a prolonged $t_{1 / 2}$ and a lower CL without a significant difference in $\mathrm{V}_{\mathrm{d}}$ were found in the ECMO group based on a subgroup analysis using neonates with $\mathrm{SCr}<0.5 \mathrm{mg} / \mathrm{dL}$.
Similar previous studies have reported inconsistent results, and no study has been conducted on Asian infants. The first study on this topic was conducted on six neonates and reported that there were no significant differences in the pharmacokinetic parameters of vancomycin in neonates undergoing ECMO. In that study, a historical control was employed as the comparison group and neonates whose $\mathrm{SCr}$ exceeded $1.5 \mathrm{mg} / \mathrm{dL}$ were excluded. ${ }^{13}$ Amaker et al obtained pharmacokinetic parameters

Table 3 Comparisons of serum vancomycin concentrations and pharmacokinetic parameters between the ECMO and non-ECMO groups

\begin{tabular}{|c|c|c|c|}
\hline & $\operatorname{ECMO}(n=75)$ & Non-ECMO(n=69) & P-values \\
\hline Trough concentrations (mg/L) & $17.86 \pm 10.04$ & $10.94 \pm 6.93$ & $<0.001$ \\
\hline Median (IQR) & $15.00(10.50-24.20)$ & $8.30(6.65-13.60)$ & \\
\hline$<5 \mathrm{mg} / \mathrm{L}, \mathrm{n}(\%)$ & $3(4.0)$ & $5(7.2)$ & $<0.001$ \\
\hline $5-10 \mathrm{mg} / \mathrm{L}$ & $11(14.7)$ & $37(53.6)$ & \\
\hline $10-15 \mathrm{mg} / \mathrm{L}$ & $23(30.7)$ & $14(20.3)$ & \\
\hline $15-20 \mathrm{mg} / \mathrm{L}$ & $11(14.7)$ & $8(11.6)$ & \\
\hline$>20 \mathrm{mg} / \mathrm{L}$ & $27(36)$ & $5(7.2)$ & \\
\hline $\begin{array}{l}\text { Peak concentrations (mg/L) } \\
\text { Median (IQR) }\end{array}$ & $\begin{array}{l}31.51 \pm 12.82 \\
29.40(21.60-39.70)\end{array}$ & $\begin{array}{l}23.43 \pm 9.65 \\
21.10(16.85-27.20)\end{array}$ & $<0.001$ \\
\hline $\begin{array}{l}\mathrm{V}_{\mathrm{d}}(\mathrm{L} / \mathrm{kg}) \\
\text { Median (IQR) }\end{array}$ & $\begin{array}{l}0.63 \pm 0.30 \\
0.55(0.48-0.72)\end{array}$ & $\begin{array}{l}0.57 \pm 0.14 \\
0.56(0.46-0.68)\end{array}$ & 0.596 \\
\hline $\begin{array}{l}\mathrm{t}_{1 / 2}(\mathrm{hr}) \\
\text { Median (IQR) }\end{array}$ & $\begin{array}{l}17.45 \pm 11.01 \\
13.70(9.62-22.40)\end{array}$ & $\begin{array}{l}5.92 \pm 2.70 \\
5.50(3.97-7.38)\end{array}$ & $<0.001$ \\
\hline $\mathrm{k}\left(\mathrm{hr} r^{-1}\right)$ & $0.06 \pm 0.04$ & $0.14 \pm 0.06$ & $<0.001$ \\
\hline $\begin{array}{l}\mathrm{CL}(\mathrm{L} / \mathrm{kg} / \mathrm{hr}) \\
\text { Median (IQR) }\end{array}$ & $\begin{array}{l}0.03 \pm 0.02 \\
0.03(0.02-0.04)\end{array}$ & $\begin{array}{l}0.08 \pm 0.05 \\
0.07(0.05-0.09)\end{array}$ & $<0.001$ \\
\hline
\end{tabular}

Data are presented as the mean \pm SD or median (IQR).

$\mathrm{AUC}_{24^{\prime}}$, area under the curve for $24 \mathrm{hr} ; \mathrm{CL}$, clearance of vancomycin related to weight; $\mathrm{ECMO}$, Extracorporeal membrane oxygenation;IQR, interquartile range; $\mathrm{V}_{\mathrm{d}}$, volume of

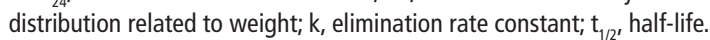


Table 4 Vancomycin pharmacokinetic parameters based on serum creatinine values in patients undergoing ECMO

\begin{tabular}{lllllr}
\hline $\begin{array}{l}\mathrm{SCr}(\mathrm{mg} / \\
\mathrm{dL})\end{array}$ & $\mathbf{n}$ & $\mathrm{Vd}(\mathrm{L} / \mathrm{kg})$ & $\mathrm{t}_{1 / 2}(\mathrm{hr})$ & $\mathrm{k}\left(\mathrm{hr}^{-1}\right)$ & $\mathrm{CL}(\mathrm{L} / \mathrm{kg} / \mathrm{hr})$ \\
\hline$<0.5$ & 17 & $0.75 \pm 0.41$ & $11.52 \pm 6.31$ & $0.08 \pm 0.04$ & $0.05 \pm 0.02$ \\
$0.5-0.9$ & 26 & $0.62 \pm 0.27$ & $12.31 \pm 4.88$ & $0.07 \pm 0.03$ & $0.04 \pm 0.02$ \\
$1.0-1.4$ & 14 & $0.51 \pm 0.18$ & $16.13 \pm 6.93$ & $0.05 \pm 0.17$ & $0.02 \pm 0.01$ \\
$\geq 1.5$ & 15 & $0.63 \pm 0.30$ & $31.53 \pm 11.45$ & $0.06 \pm 0.04$ & $0.01 \pm 0.02$ \\
P-values & & 0.141 & $<0.001$ & $<0.001$ & $<0.001$ \\
\hline
\end{tabular}

Data are presented as the mean \pm SD.

$\mathrm{CL}$, clearance of vancomycin related to weight; ECMO, Extracorporeal membrane oxygenation; $\mathrm{SCr}$, serum creatinine; $\mathrm{V}_{\mathrm{d}^{\prime}}$ volume of distribution related to weight; $\mathrm{k}$, elimination rate constant; $t_{1 / 2}$, half-life.

from 12 infants undergoing ECMO, and the results were also compared with previously published data. ${ }^{14}$ They reported increased $\mathrm{V}_{\mathrm{d}}$ and $\mathrm{t}_{1 / 2}$ and decreased CL in infants undergoing ECMO. ${ }^{14}$ Another study showed that, among the vancomycin pharmacokinetic parameters measured, only $t_{1 / 2}$ increased significantly in neonates undergoing ECMO relative to those not receiving ECMO. ${ }^{15}$ Unlike the first two studies, this study had an appropriate control group. However, the sample size was still small $(n=30)$. Our study has the strengths of a relatively large sample size $(n=50)$ and the use of an appropriate control group. Moreover, this is the first study of vancomycin pharmacokinetics in Asian neonates receiving ECMO.

Studies using gentamicin have shown that the $\mathrm{V}_{\mathrm{d}}$ of hydrophilic drugs can be increased during ECMO. This finding can be explained by the increased circulating volume caused by the dilution of blood during ECMO. ${ }^{19}{ }^{20}$ Although vancomycin is a hydrophilic compound, our results did not show a significant difference in the $\mathrm{V}_{\mathrm{d}}$ between the two groups. One possible reason could be that vancomycin is less hydrophilic than gentamicin. ${ }^{21}$ However, further research should be conducted for more clarification.

The CL values for the neonates in our study were comparable to previously reported values. In our study, the CL of vancomycin in neonates receiving ECMO was $0.03 \pm 0.02 \mathrm{~L} / \mathrm{kg} / \mathrm{hr}$, compared with 0.04 to $0.05 \mathrm{~L} / \mathrm{kg} / \mathrm{hr}$ in previous studies. ${ }^{14} 15$ In the non-ECMO group, the CL values $(0.08 \pm 0.05 \mathrm{~L} / \mathrm{kg} / \mathrm{hr})$ were also similar to those from other studies $(0.07 \sim 0.10 \mathrm{~L} / \mathrm{hr} /$ $\mathrm{kg}$ ) using the Nonlinear Mixed Effects Modelling (NONMEM) program. ${ }^{22-24}$ Consistent with previous studies, ${ }^{25} 26$ our study showed that vancomycin CL was strongly associated with SCr, which is a measure of renal function. To achieve the target

Table 5 Vancomycin pharmacokinetic parameters in neonates with $\mathrm{SCR}<0.5 \mathrm{mg} / \mathrm{dL}$

\begin{tabular}{lllc}
\hline & ECMO & Non-ECMO & P values \\
\hline Patients & 13 & 26 & \\
Cases & 17 & 56 & \\
$\mathrm{~V}_{\mathrm{d}}(\mathrm{L} / \mathrm{kg})$ & $0.75 \pm 0.41$ & $0.59 \pm 0.14$ & 0.069 \\
$\mathrm{t}_{1 / 2}(\mathrm{hr})$ & $11.52 \pm 6.31$ & $5.44 \pm 2.36$ & $<0.001$ \\
Median (IQR) & $10.59(6.70-14.75)$ & $5.06(3.70-6.71)$ & \\
$\mathrm{k}\left(\mathrm{hr}^{-1}\right)$ & $0.08 \pm 0.04$ & $0.15 \pm 0.06$ & $<0.001$ \\
$\mathrm{CL}(\mathrm{L} / \mathrm{kg} / \mathrm{hr})$ & $0.05 \pm 0.02$ & $0.09 \pm 0.05$ & 0.001 \\
Median (IQR) & $0.05(0.03-0.06)$ & $0.08(0.06-0.10)$ & \\
\hline
\end{tabular}

Data are presented as the mean \pm SD or median (IQR).

$\mathrm{CL}$, clearance of vancomycin related to weight; $\mathrm{ECMO}$, extracorporeal membrane oxygenation; $\mathrm{IQR}$, interquartile range; $\mathrm{SCr}$, serum creatinine; $\mathrm{V}_{\mathrm{d}^{\prime}}$, volume of distribution related to weight; $k$, elimination rate constant; $t_{1 / 2^{\prime}}$, half-life. therapeutic range of vancomycin, an extended dosing interval is suggested for patients undergoing ECMO.

Because SCr was significantly higher in the ECMO group than in the non-ECMO group, and vancomycin CL showed a negative correlation with SCr, an additional subgroup analysis was conducted in patients with SCr $<0.5 \mathrm{mg} / \mathrm{dL}$. The pharmacokinetic differences between the ECMO and non-ECMO groups in patients with SCr $<0.5 \mathrm{mg} / \mathrm{dL}$ were similar to those analysed in all study patients.

Unlike our results, a study using adult patients with normal SCr showed similar $\mathrm{V}_{\mathrm{d}}$ and CL for vancomycin in patients with ECMO compared with those without ECMO. ${ }^{27}$ This was explained that the decreased vancomycin CL in neonates with ECMO was attributable to immature hepatic and renal antibiotic pathways rather than the ECMO circuitry itself. ${ }^{28}$

To the best of our knowledge, this is the first evaluation of vancomycin pharmacokinetics in Asian neonates undergoing ECMO. In particular, this is the first instance in which vancomycin pharmacokinetic parameters from a subpopulation with SCr $<0.5 \mathrm{mg} / \mathrm{dL}$ were compared between patients with and without ECMO. However, while some studies have reported that the pulsatility of pumps could affect the alteration of renal function, ${ }^{29} 30$ information about ECMO circuits could not be gathered in this study due to its retrospective nature. Given the limitations of this study, our study requires further independent validation using more robust prospective designs.

\section{CONCLUSIONS}

This study suggests that alterations in the pharmacokinetics of vancomycin occur in neonates on ECMO. In the ECMO group, the $t_{1 / 2}$ was significantly prolonged compared with that in the non-ECMO group. The values for $\mathrm{k}$ and $\mathrm{CL}$ decreased significantly in the ECMO group relative to those in the non-ECMO group. No significant difference was found in the $V_{d}$ measured

\section{What this paper adds}

What is already known on this subject

- Extracorporeal membrane oxygenation (ECMO) is used for the management of severe respiratory or cardiorespiratory failure in neonates.

- Because ECMO increases the circulating blood volume and transiently alters renal function, the pharmacokinetics of many drugs can be affected by ECMO.

- Several studies have been conducted on the effects of ECMO on the pharmacokinetics of vancomycin in neonates and infants. However, most studies had small sample sizes and lacked adequate control groups. Moreover, conflicting results have been reported.

What this study adds

- Alterations in the pharmacokinetics of vancomycin occurred in neonates on ECMO. In the ECMO group, half-life was significantly prolonged compared with that in the non-ECMO group. The values for elimination rate were constant and clearance decreased significantly in the ECMO group relative to those in the non-ECMO group. No significant difference was found in the volume of distribution measured for the two groups.

- Dosing adjustments of vancomycin and close therapeutic drug monitoring are required for the safe and effective management of neonates during ECMO. 
for the two groups. Dosing adjustments of vancomycin and close TDM are required for the safe and effective management of neonates during ECMO.

Acknowledgements This research was supported by the Basic Science Research Program through the National Research Foundation of Korea (NRF) funded by the Ministry of Education (NRF-2015R1D1A1A01057223).

Contributors SHA, EML and HSG participated in research design. SHA, EML, JYK and HSG conducted research. SHA, EML and HSG performed data analysis. SHA, EML and HSG wrote or contributed to the writing of the manuscript. All authors read and approved the final manuscript.

Funding This research was supported by the Basic Science Research Program through the National Research Foundation of Korea (NRF) funded by the Ministry of Education (NRF-2015R1D1A1A01057223).

Competing interests None declared.

Patient consent for publication Not required.

Provenance and peer review Not commissioned; externally peer reviewed.

ORCID iD

Hye sun Gwak http://orcid.org/0000-0003-0278-2563

\section{REFERENCES}

1 Bartlett RH, Gazzaniga AB, Toomasian J, et al. Extracorporeal membrane oxygenation (ECMO) in neonatal respiratory failure. 100 cases. Ann Surg 1986;204:236-45.

2 Bartlett RH. Extracorporeal life support: history and new directions. Asaio J 2005:51:487-9.

3 Bartlett RH, Gattinoni L. Current status of extracorporeal life support (ECMO) for cardiopulmonary failure. Minerva Anestesiol 2010;76:534-40.

4 Lindstrom SJ, Pellegrino VA, Butt WW. Extracorporeal membrane oxygenation. Med J Aust 2009;191:178-82.

5 Buck ML. Pharmacokinetic changes during extracorporeal membrane oxygenation: implications for drug therapy of neonates. Clin Pharmacokinet 2003;42:403-17.

6 Marasco SF, Lukas G, McDonald M, et al. Review of ECMO (extra corporeal membrane oxygenation) support in critically ill adult patients. Heart, Lung and Circulation 2008:17:\$41-S47.

7 Lawson G, Mulla H, Upton DR, et al. Drug disposition during extracorporeal membrane oxygenation (ECMO). Paediatric Perinatal Drug Ther 2001;4:109-20.

8 Morselli PL, Franco-Morselli R, Bossi L. Clinical pharmacokinetics in newborns and infants. age-related differences and therapeutic implications. Clin Pharmacokinet 1980;5:485-527.

9 Radde IC. Renal function and elimination of drugs during development. In: Radde IC, Macleod SM, eds. Pediatric pharmacology and therapeutics. 87. St. Louis: Mosby Year Book, 1993

10 de Hoog M, Mouton JW, van den Anker JN. Vancomycin: pharmacokinetics and administration regimens in neonates. Clin Pharmacokinet 2004;43:417-40.

11 Jarrett RV, Marinkovich GA, Gayle EL, et al. Individualized pharmacokinetic profiles to compute vancomycin dosage and dosing interval in preterm infants. Pediatr Infect Dis J 1993;12:156-7.
12 Rodvold KA, Gentry CA, Plank GS, et al. Bayesian forecasting of serum vancomycin concentrations in neonates and infants. Ther Drug Monit 1995;17:239-46.

13 Hoie E, Swigart S, Leuschen M. Vancomycin pharmacokinetics in infants undergoing extracorporeal membrane oxygenation. Clin Pharmacokinet 1990;9:711-5.

14 Amaker RD, DiPiro JT, Bhatia J. Pharmacokinetics of vancomycin in critically ill infants undergoing extracorporeal membrane oxygenation. Antimicrob Agents Chemother 1996:40:1139-42.

15 Buck ML. Vancomycin pharmacokinetics in neonates receiving extracorporeal membrane oxygenation. Pharmacotherapy 1998;18:1082-6.

16 Suryadevara M, Steidl KE, Probst LA, et al. Inappropriate vancomycin therapeutic drug monitoring in hospitalized pediatric patients increases pediatric trauma and hospital costs. J Pediatr Pharmacol Ther 2012;17:159-65.

17 Seng JJB, Yong MHA, Peh ZX, et al. Appropriateness of vancomycin therapeutic drug monitoring and its outcomes among non-dialysis patients in a tertiary hospital in Singapore. Int I Clin Pharm 2018:40:977-81.

18 Young TE, Neofax MB. Neofax, ed 17, revised. Raleigh, NC: Acorn Publishing, 2004.

19 Cohen P, Collart L, Prober CG, et al. Gentamicin pharmacokinetics in neonates undergoing extracorporal membrane oxygenation. Pediatr Infect Dis J 1990;9:562-5.

20 Dodge WF, Jelliffe RW, Zwischenberger JB, et al. Population pharmacokinetic models: effect of explicit versus assumed constant serum concentration assay error patterns upon parameter values of gentamicin in infants on and off extracorporeal membrane oxygenation. Ther Drug Monit 1994;16:552-9.

21 National Center for Biotechnology Information. PubChem compound database; CID=14969. Available: https://pubchem.ncbi.nlm.nih.gov/compound/14969 [Accessed 4 Dec 2018].

22 Capparelli EV, Lane JR, Romanowski GL, et al. The influences of renal function and maturation on vancomycin elimination in newborns and infants. I Clin Pharmacol 2001:41:927-34.

23 Marqués-Miñana MR, Saadeddin A, Peris JE. Population pharmacokinetic analysis of vancomycin in neonates. A new proposal of initial dosage guideline. Br J Clin Pharmacol 2010;70:713-20.

24 De Cock RF, Allegaert K, Brussee JM, et al. Simultaneous pharmacokinetic modeling of gentamicin, tobramycin and vancomycin clearance from neonates to adults: towards a semi-physiological function for maturation in glomerular filtration. Pharm Res 2014;31:2643-54.

25 Rodvold KA, Blum RA, Fischer JH, et al. Vancomycin pharmacokinetics in patients with various degrees of renal function. Antimicrob Agents Chemother 1988;32:848-52.

26 Marsot A, Boulamery A, Bruguerolle B, et al. Vancomycin: a review of population pharmacokinetic analyses. Clin Pharmacokinet 2012;51:1-13.

27 Donadello K, Roberts JA, Cristallini S, et al. Vancomycin population pharmacokinetics during extracorporeal membrane oxygenation therapy: a matched cohort study. Crit Care 2014;18.

28 Alcorn J, McNamara PJ. Pharmacokinetics in the newborn. Adv Drug Deliv Rev 2003:55:667-86

$29 \mathrm{Kim} \mathrm{HK}$, Son HS, Fang YH, et al. The effects of pulsatile flow upon renal tissue perfusion during cardiopulmonary bypass: a comparative study of pulsatile and nonpulsatile flow. Asaio / 2005;51:30-6.

30 Many M, Soroff HS, Birtwell WC, et al. The physiologic role of pulsatile and nonpulsatile blood flow. 3. Effects of unilateral renal artery depulsation. Arch Surg 1968:97:917-23. 